\title{
TEORIA CRÍTICA E INFÂNCIA: A CARACTERIZAÇÃO DO CONCEITO NO CONTEXTO DE EXPROPRIAÇÃO DAS EXPERIÊNCIAS FORMATIVAS
}

\author{
CRITICAL THEORY AND CHILDHOOD: THE CHARACTERIZATION OF THE \\ CONCEPT IN EXPROPRIATION CONTEXT OF FORMATIVE EXPERIENCES
}

\author{
Andréa CALDERAN ${ }^{1}$ \\ Luiz Roberto GOMES ${ }^{2}$
}

\begin{abstract}
RESUMO: O artigo aborda o conceito de infância na perspectiva dos autores da Teoria Crítica. O objetivo foi compreender a criança e a infância a partir das possibilidades de experiências formativas. O estudo pautou-se, principalmente, nos escritos de Adorno e Horkheimer, Walter Benjamin e Giorgio Agamben. Trata-se de um conjunto de reflexões que procuram analisar o processo de expropriação da experiência, no contexto da indústria cultural e da sociedade de consumo. A educação voltada à emancipação não pode prescindir da capacidade de realização de experiências contidas no universo da infância, como criança, ou como potencialidade humana capaz de produzir cultura.
\end{abstract}

PALAVRAS-CHAVE: Teoria crítica. Infância. Expropriação da experiência. Educação.

ABSTRACT: The article discusses the concept of childhood from the perspective of the authors of Critical Theory. The goal was to understand the child and childhood from the possibilities of formative experiences. The study was based mainly on the writings of Adorno and Horkheimer, Walter Benjamin and Giorgio Agamben. This is a set of reflections that seek to analyze the process of expropriation of experience in the context of the cultural industry and consumer society. The education focused on emancipation can not do without the realization capacity of experience contained in childhood universe as a child, or as a human potential capable of producing culture.

KEYWORDS: Critical theory. Childhood. Expropriation experience. Education.

\section{Introdução}

Em um estudo anterior intitulado “A construção histórico-cultural do conceito de criança e infância: apontamentos teóricos" (CALDERAN; PEREZ, 2015) constatou-se que a análise do conceito de infância tem sido cada vez mais recorrente. Por vezes, estes estudos

${ }^{1}$ Universidade Federal de São Carlos (UFSCar), São Carlos - SP - Brasil. Mestranda no Programa de PósGraduação em Educação. E-mail: an.calderan@gmail.com.

${ }^{2}$ Universidade Federal de São Carlos (UFSCar), São Carlos - SP - Brasil. Professor Permanente do Programa de Pós-graduação em Educação. E-mail: luizrgomes.@ufscar.br.

Doxa: Rev. Bras. Psicol. Educ., Araraquara, v.19, n.2, p. 270-282, jul./dez. 2017. 
vêm destacando historiadores e sociólogos que discutem a história da criança e sua infância como algo preocupante colocando, até mesmo, o Desaparecimento da Infância (POSTMAN, 1999) em discussão. Para estudar a infância, alguns autores tomam como ponto de partida diferentes perspectivas/metodologias, por exemplo, a perspectiva histórico-cultural compreende a criança como um ser social, que ao aprender se desenvolve. A Sociologia da Infância, que vem sendo fortemente utilizada como metodologia para a compreensão da infância, consideraas particularidades culturais da criança, negando a ideia de uma infância universal. A partir de alguns destes exemplos eno contexto das diversas perspectivas existentes sobre a infância, tomaremos a Teoria Crítica da Sociedade, como contraponto crítico de análise ao conceito de Infância. Afinal, como os autores da Teoria Crítica compreendem a criança e a infância? Portanto, o objetivo deste trabalho é tentar compreender o conceito de infância, no sentido das análises feitas pelos autores da Teoria Crítica e que podem nos ajudar a realizar um contraponto crítico sob à forma como o conceito de infância tem sido empregado hoje.

\section{Teoria crítica e infância}

A reflexão sobre o conceito de infância ocupa um lugar de destaque na tradição da Teoria Crítica da Sociedade. A ênfase na pesquisa empírica, multidisciplinar, crítica, e orientada para a emancipação, sempre foi uma marca do Instituto de Pesquisa Social em Frankfurt, desde os anos de sua fundação e consolidação (1924 - 1950), até constituição epistemológica daquilo que se denomina Escola de Frankfurt ${ }^{3}$, e que ficou conhecida como "Teoria Crítica da Sociedade" (WIGGERSHAUS, 2002). Trata-se de uma teoria social-crítica que procura analisar a dominação ideológica contida nos processos de reprodução social, e que se manifestam em fenômenos culturais, institucionais e sócio-políticos. A investigação e análise das condições objetivas da sociedade, como os frankfurtianos da primeira geração a denominavam, constituem, ainda hoje, o programa por excelência do empreendimento científico da Teoria Crítica.

Cabe salientar, que o projeto epistemológico da Teoria Crítica, desde os trabalhos deseus pioneiros, consistia na consolidação de outra perspectiva de teoria social, capaz de se contrapor à teoria social hegemônica, de natureza positivista, e que Horkheimer (1987) denominou Teoria Tradicional. Isso implica outra postura em relação à função social da

\footnotetext{
${ }^{3}$ Sobre o conceito de teoria crítica e a especificidade da Escola de Frankfurt Cf. Horkheimer (1987) e Nobre
} (2004). 
própria ciência e da sociedade. Na perspectiva crítica, a teoria sevincula à prática social, enquanto a pesquisa social deve ir além da dimensão da especialidade e transformar-se em ciência interdisciplinar superando, por assim dizer, a limitaçãoinstrumental e normativa. A teoria deve ultrapassar, ainda, o recorte meramente especulativo, ou seja, filosófico-social da ideia de sociedade, pela crítica imanente da ordem social “danificada”. É na práxis social (MARX, 1978), ou seja, na forma como os homens vivem em sociedade, que é possível compreender e superar as contradições sociais. Essa concepção determina o procedimento epistemológico de análise dos objetos empíricos, e que dão sustentação aos conceitos, tais como o de Infância.

A nossa análise sobre o conceito de infância considerou, inicialmente, as obras História social da criança e da família do historiador Philippe Ariès (1973) e O desaparecimento da infância de Neil Postman (1999).

Ariès (1973) destaca dois pontos principais na história da criança: a ausência do sentimento de infância e o aparecimento da infância. Segundo este autor, a constatação sobre a falta do sentimento de infância surgiu por volta do século XII/XIII, no qual as crianças eram vistas como adultos em miniaturas: desempenhavam as mesmas tarefas de um adulto, se vestiam e se portavam como tal. Além disso, participavam de festividades, danças, reuniões e jogos de adulto. Esses "adultos em miniatura" eram vistos como úteis à sociedade, e acreditava-se que em contato com os mais velhos é que se dava o desenvolvimento. $\mathrm{O}$ aparecimento do conceito de infância se dá a partir do século XVII, com as interferências dos moralistas, do poder público e da igreja que passaram a compreender as particularidades da criança, consequentemente, a infância.

Postman (1999) também destaca dois aspectos, os mesmos da obra de Ariés (1973), entretanto, acrescenta outros marcos na construção da infância, e se estende mostrando sua preocupação com a infância contemporânea. O ponto desta obra em destaque é o momento da prensa tipográfica como hierarquização do conhecimento, e consequentemente, a necessidade de alfabetização e criação de escolas. Desta forma, a criança passou a ser civilizada, treinada para o mundo adulto, além de passar a frequentar a escola. No século XVI ao XIX, a criança passa a ser valorizada, e a infância passa a ser vista como direito das crianças de todas as camadas sociais. Outro ponto importante é o surgimento da televisão, que enfraqueceu a hierarquização do conhecimento, pois não se precisava saber ler e escrever para compreender as informações. Com esses dados, o autor passa a destacar sua preocupação, visto que as crianças estão cada vez mais tendo acesso ao mundo adulto, e o surgimento da televisão passou a facilitar esse acesso, influenciando a cultura infantil. Esse fenômeno nos remete a 
similaridade do contexto de quando não se existia sentimento de infância, desta vez, porém, não pela falta do sentimento de infância, mas pela influência de uma cultura sobre a outra, refletida massivamente pela mídia em traços microfísicos como: crianças com as mesmas vestimentas de um adulto, mesmos desejos, comportamentos, atitudes, dentre outros.

Com este breve panorama, observamos alguns pontos similares no diagnóstico realizado pelos autores supracitados e os autores da Teoria Crítica. A Teoria Crítica surge com o proposito de compreender os fenômenos sociais, culturais, entre outros, a partir de Marx. Neste contexto, destaca-se o texto "A indústria cultural" de Theodor Adorno e Horkheimer, que foi publicado na obra Dialética do Esclarecimento (1985), no qual ressalta a televisão como elemento forte da indústria cultural, que interfere cada vez mais nos fenômenos sociais, culturais e na autonomia do indivíduo. Visto isso, faz-se necessário destacar e discutir tais interferências na vida dos indivíduos, dos adultos e das crianças; em que prevalece cada vez mais os comportamentos e concepções da sociedade do consumo.

Um tema sempre recorrente nas obras de Adorno, é a preocupação com o processo de empobrecimento das experiênciasformativas. $\mathrm{O}$ empobrecimento se dá pelasmudanças no processo do desenvolvimento científico, pelo avanço da industrialização, pelas formas sofisticadas de dominação social, entre outros fatores, que fazem a sociedade cada vez mais submissa à politica capitalista. Os avanços industriaisfomentaram a modernidade e a sofisticação da tecnologia, mas a sociedade cada vez mais administrada fez gerar também a alienação e a submissão dos indivíduos à sociedade do consumo. Tal alienação foi resultado da industrialização da cultura, ou seja, "A indústria cultural”, conceito cunhado por Adorno e Horkheimer (1985). Para Duarte (2007), a denominação “indústria cultural”:

[...] evoca a idéia, intencionalmente polêmica, de que a cultura deixou de ser uma decorrência espontânea da condição humana, na qual se expressam tradicionalmente, em termos estéticos, seus anseios e projeções mais recônditos, para se tornar mais um campo de exploração econômica, administrando de cima para baixo e voltado apenas para os objetivos supramencionados de produzir lucros e de garantir adesão do sistema capitalista por parte do público. (DUARTE, 2007, p. 9).

Neste contexto deindustrialização, a cultura também se torna um campo de exploração econômica, que favorece o sistema capitalista, e estimula cada vez mais a venda de produtos culturais, que passam a ser um objeto de consumo. Para Adorno e Horkheimer (1985, p. 179): 
lado, antecipadamente, organizar essas necessidades de modo que o consumidor a elas se prenda, sempre e tão só como eterno consumidor, como objeto da indústria cultural.

Em outra passagem, os autores continuam:

O efeito conjunto da Indústria Cultural é o de uma antidesmistificação, a de um anti-iluminismo (anti-Auflkärung); nela, como Horkheimer e eu dissemos, a desmistificação, a Aufklärung, a saber a dominação técnica progressiva se transforma em engodo das massas, isto é, em meio de tolher a sua consciência. Ela impede a formação de indivíduos autônomos, independentes, capazes de julgar e de decidir conscientemente. (ADORNO; HORKHEIMER, 1985, p. 295).

Ainda, destaca-se o conceito de Cultura de Massa, na qual a cultura passa a ser produzida para atingir a massa popular sem distinções sociais, etárias, entre outros. Adorno (1984, p. 331 apud MAAR, 2003, p. 465) define que:

Os homens dão seu assentimento à cultura de massas porque sabem que aqui aprenderão os hábitos ("mores") de que precisam na vida monopolizada como passaporte. Este só é válido quando pago com sangue, com a total cessão da vida, com a obediência subalterna face à odiosa imposição. Por isto, e não pela estultificação das massas que os inimigos destas produzem e os amigos lamentam, a cultura de massas é tão irresistível.

Dessa forma, o conceito de Halbbildung (Semiformação) definido como “[...] o espírito tomado pelo caráter de fetiche da mercadoria.” (ADORNO, 2010, p. 25) ganha destaque, visto que as consequências da Indústria Cultural não enriquece o indivíduo para um ser autônomo, e sim, um ser passível, fácil de ser alienado. Ou seja, o indivíduo sente-se a falsa impressão de estar adquirindo cultura, entretanto, a cultura cedida a ele acaba se transformando em semicultura.

Percebe-se até aqui que a Indústria Cultural além de industrializar o conhecimento, sua produção em massa, não leva em consideração as distinções etárias, ou seja, o primeiro traço demarcado aqui é que o adulto, assim como a criança possui acesso fácil a essa industrialização cultural massificada, na qualnão agrega conhecimento efetivo, carente de cultura significativa, sendo esta apenas padronizada. Para Adorno e Horkheimer (1985, p. 295):

Se as massas são injustamente difamadas do alto como tais, é também a própria indústria cultural que as transforma nas massas que ela depois despreza, e impede de atingir a emancipação, para qual os próprios homens estariam tão maduros quanto as forças produtivas da época o permitiriam. 
Para Adorno "O mundo inteiro é forçado a passar pelo filtro da indústria cultural." (ADORNO; HORKHEIMER, 1985, p. 118). Sob tal condição, é necessário resistir pela via da autorreflexão crítica sobre os processos de massificação e exploração. Em sua obra Educação e emancipação, Adorno (1995, p. 141-142) assinala a urgência em promover um modelo de educação emancipatória, a fim de evitar o acontecimento de novas barbáries, destacando assim, as condições para que haja uma democracia efetiva:

\begin{abstract}
A seguir, e assumindo o risco, gostaria de apresentar a minha concepção inicial de educação. Evidentemente não a assim chamada modelagem de pessoas, porque não temos o direito de modelar pessoas a partir do seu exterior; mas também não a mera transmissão de conhecimentos, cuja característica de coisa morta já foi mais do que destacada, mas a produção de uma consciência verdadeira. Isto seria inclusive da maior importância política; sua idéia, se é permitido dizer assim, é uma exigência política. Isto é: uma democracia com o dever de não apenas funcionar, mas operar conforme seu conceito, demanda pessoas emancipadas. Uma democracia efetiva só pode ser imaginada enquanto uma sociedade de quem é emancipado.
\end{abstract}

Embora Adorno (1995) não discuta diretamente o conceito de criança e infância, nos seus escritos acerca da educação, ele faz várias menções à educação na infância, considerado por ele como uma espécie de condição do futuro democrático. Embora este autor não discorra específicamente sobre como se daria a educação para a sensibilidade estética da criança, as reflexões contidas na obra Teoria Estética (ADORNO, 1970) seriam muito oportunas, no sentido de se definir, desde a infância, os elementos básicos de uma educação emancipadora, voltada a valorização de experiências estéticas significativas.

Outro autor da Teoria Crítica, que merece destaque é Walter Benjamin, que tratou especificamente do tema aqui em pauta: narra sua infância através das lembranças de sua memória, traçando concepções de infância, formação e cultura lúdica, que serão discutidos a seguir. Antes, conforme destacamos anteriormente, na história da criança descrita por Ariès (1973), vale registrar aqui, a ênfase utilizada por Marchi (2011, p. 222) em seu artigo intitulado "Walter Benjamin e a infância: apontamentos impressionistas sobre sua(s) narrativa(s) a partir de narrativas diversas" no qual ressalta que:

Se Ariès surpreendeu o mundo acadêmico, em 1960, com a publicação do seu clássico estudo sobre a história social da criança e da família, só podemos imaginar dois motivos para que não seja creditado a WB [Walter Benjamin] esse pioneirismo: primeiro, porque não há em sua obra uma sistematização da temática da infância; segundo, porque ele não se propôs, tal qual o historiador francês, a realizar uma pesquisa histórica sobre o 
surgimento da infância na Europa. Mas, o que WB fez de forma muito mais sutil e, talvez por isso mesmo, tão marcante, foi elevar, já nos anos 20 do século XX, a criança ao estatuto de sujeito digno de observação e nota. Dessa forma, Benjamin pode ser considerado, para além de um historiador sociocultural da infância, um pioneiro da abordagem sociológica que, somente a partir dos anos 80 do século XX, vai olhar para a criança como um "ator social"; portanto, como "produtora de cultura". Sendo Benjamin praticamente contemporâneo do movimento histórico da institucionalização da infância no século XIX, podemos considerar que não havia ainda, para esse autor, o chamado distanciamento histórico do fenômeno.

Tal fato não interfere diretamente em nossa análise, entretanto, contribui para a compreensão dos escritos desses autores. Um dos textos mais importantes de Walter Benjamin é "Infância em Berlim por volta de 1900" (1993, no qual o autor trás narrativas de experiências pessoais, que sobressaem o universo e a singularidade infantil, revelados através de suas narraçõesde brincadeiras, alegrias, medos, frustrações e fantasias. Benjamin dá destaque às experiências infantis, enfatizando também, a importância da dialética de trocas de experiências entre o adulto e a criança. Vale destacar aqui, que Benjamin fora um filósofo que desde a infância pertencia à família burguesa e judia, tendo assim, contribuições ricas a sua bagagem cultural.Entretanto, percebe-se em suas obras que ele voltava-se a observar aos menos privilegiados e marginalizados.

Outra obra de grande contribuição é Reflexões sobre o brinquedo, a criança e a educação (BENJAMIN, 2002). Nesta obra, Benjamin retoma a história cultural dos brinquedos, até o período do capitalismo pós-industrial. Nesta trajetória de transformação do brinquedo, Benjamin (2002, p. 91-92) destaca o distanciamento das crianças e seus pais:

[...] em seus pequenos formatos, os voluminhos mais antigos exigiam a presença da mãe de maneira muito mais íntima; os volumes in quarto mais recentes, em sua insípida e dilatada ternura, estão antes determinados a fazer vista grossa à ausência materna. Uma emancipação do brinquedo põe-se a caminho; quanto mais a industrialização avança, tanto mais decididamente o brinquedo se subtrai ao controle da família, tornando-se cada vez mais estranho não só às crianças, mas também aos pais.

Apesar de Benjamin não escrever uma teoria sobre a educação e o brincar, ele destaca a importância das atividades lúdicas na infância para o mundo adulto. Desta forma, ele descreve a importância da ludicidade como uma forma de lidar com as angústias e comunicar com o mundo adulto. 
Não há dúvida que o brincar significa sempre libertação. Rodeadas por um mundo de gigantes, as crianças criam para si, brincando, o pequeno mundo próprio. (BENJAMIN, 2002, p. 85).

Deste modo, destaca-se mais uma vez, a importância da experiência na vida do indivíduo, sobretudo na infância. Acredita-se, portanto, que a ludicidade é capaz de proporcionarexperiências plenas, de modo prazeroso trazendo transformações significativas na subjetividade do sujeito, pois

\footnotetext{
Não são as coisas que saltam das páginas em direção à criança que as vai imaginando - a própria criança penetra nas coisas durante o contemplar, como nuvem que se impregna do esplendor colorido desse mundo pictórico. (BENJAMIN, 2002, p. 69).
}

Em seus escritos, Benjamin, também faz críticas aos brinquedos industrializados, valorizando o brincar artesanal, visto que os brinquedos "[...] quanto mais atraentes, no sentido corrente, são os brinquedos, mais se distanciam dos instrumentos de brincar; quanto mais ilimitadamente a imitação se manifesta neles, tanto mais se desviam da brincadeira viva." (BENJAMIN, 2002, p. 93). A industrialização dos brinquedos impõe formasde brincar, condicionando as crianças a aquilo que os adultos produzem, sobretudo, na sociedade digital do consumo, com apelos às imagens e a linguagem iconográfica dos Tablets, Celulares $e$

\section{Jogos Digitais.}

Um outro livro de Benjamin (2015), recentemente publicado no Brasil, e que ainda não tivemos oportunidade de aprofundar a análise é $A$ hora das crianças, publicado pela Editora Nau em 2015, que traz as conferências, resenhas de livros e histórias apresentadas por Walter Benjamin em programas de rádio de Berlim e Frankfurt, e que tinham as crianças como público-alvo. Certamente, nesse livro, o conceito de infância e de criança pode ser aprofundado.

Podemos traçar a compreensão de criança para Benjamin, visto que ele a considera como um ser ativo no contexto sócio histórico-cultural, da qual é capaz de produzir sua própria cultura, seus próprios brinquedos e fantasiar de maneira única sua própria experiência. Para que isso ocorra, retoma-se a importância do brincar, de forma criativa, dando vozes a imaginação. Também, pode se destacar a importância do distanciamento dos produtos prontos advindos da Indústria Cultural nas formas de experiências para o indivíduo, visto que ela, segundo Adorno e Horkheimer (1985, p. 120): “A indústria cultural não sublima, mas reprime e sufoca." 
Um outro autor que merece destaque aqui é Giorgio Agamben (2005) com sua obra intitulada Infância e História: destruição da experiência e origem da história. Nesta obra, o autor faz uma relação entre experiência e infância, para sugerir e agregar novas significações a esses conceitos. Para Agamben (2005, p. 59) a infância não deve ser entendida como:

[...] algo que precede cronologicamente a linguagem e que, a uma certa altura, cessa de existir para versar-se na palavra, não é um paraíso que, em um determinado momento, abandonamos para sempre a fim de falar, mas coexiste originalmente com a linguagem, constitui-se, aliás, ela mesma na expropriação que dela efetua, produzindo a cada vez o homem como sujeito.

Dessa forma, destaca-se que a infância não deve ser vista como um período passageiro, nem como um indivíduo que se tornarará um adulto, e sim, como uma infância com capacidade de potência.

O autor ainda apresenta o conceito de experiência, logo no início de sua obra, no qual destacamos:

Todo discurso sobre a experiência deve partir atualmente da constatação de que ela não é mais algo que ainda nos seja dado fazer. Pois assim como foi privado da sua biografia, o homem contemporâneo foi expropriado de sua experiência: aliás, a incapacidade de fazer e transmitir experiências talvez seja um dos poucos dados certos de que disponha sobre si mesmo (AGAMBEN, 2005, p. 21-22).

Neste contexto, Agamben (2005, p. 22-23) discorre sobre a dificuldade de exercer experiências na atual sociedade, fazendo relação entre experiência e autoridade:

\begin{abstract}
Porque a experiência tem o seu necessário correlato não no conhecimento, mas na autoridade, ou seja, na palavra e no conto, e hoje ninguém mais parece dispor de autoridade suficiente para garantir uma experiência, e se dela dispõe, nem ao menos o aflora a ideia de fundamentar em uma experiência a própria autoridade. Ao contrário, o que caracteriza o tempo presente é que toda autoridade tem o seu fundamento no "inexperienciável", e ninguém admitiria aceitar como válida uma autoridade cujo único título de legitimação fosse uma experiência. [...] O que não significa que hoje não existam mais experiências. Mas estas se efetuam fora do homem. E, curiosamente, o homem olha para elas com alívio. [...] a esmagadora maioria da humanidade recusa-se hoje a experimentá-las: prefere que seja a máquina fotográfica a ter a experiência delas.
\end{abstract}

A princípio, em seu escrito, o autor discute o empobrecimento da experiência, a partir das guerras mundiais. Entretanto, mesmo sem a necessidade da existência do contexto de horror de uma guerra, o autor passa a discutir o empobrecimento da experiência, agora, pela 
influência da Industria Cultural, pois, “[...] o dia-a-dia do homem contemporâneo não contém quase nada que seja traduzível em experiência." (AGAMBEN, 2005, p. 21-22). Tal reflexão trazida pelo autor nos faz refletir ainda mais sobre o desenvolvimento tecnológico, no qual ocupa cada vez mais o cotidiano das pessoas, tornando cada vez mais escasso, não só as relações humanas, como também, a vivência de novas experiências. Isso vem a se refletir no cotidiano infantil, visto que estas estão cada vez mais inseridasno mundo tecnológico.

Agamben (2005) sugere, portanto, a procura de um novo lugar para a experiência, destacando a infância como lugar propício. Dessa forma, o autor destaca infância, experiência e linguagem como uma conexão. Assim sendo, mostra que a infânciaé uma condição da experiência humana, na qual consiste a busca entre experiência e linguagem. Ou seja, destacase a dependência entre Infância e Linguagem para a condição de existência do homem.

Para Kohan (2007, p. 122), Agamben:

[...] mostra-nos, muito sugestivamente, que, se bem é verdade que a infância é a ausência de linguagem, não é menos verdade que a adultícia é a ausência da possibilidade de se inscrever na linguagem, porque já se está dentro dela, ou porque se impossibilitou de entrar durante a infância. Em outras palavras, se tirarmos os casos excepcionais, são sempre as crianças e não os adultos que aprendem a falar. Quem entra na linguagem pela primeira vez é a infância, a aprendizagem da linguagem está ligada à disposição infantil, ao abandonarmos a infância, deixamos a possibilidade de entrar na linguagem.

Em suma, sob a concepção desses três autores, percebemos traços comuns quando se diz respeito a formação do sujeito. A possibilidade de experiências formativas significativas pode ser considerada como um elemento comum de fundamentação do conceito de infância. No caso específico dos processos educativos, tomar a infância como um conceito amplo capaz de fomentar experiências, pode ser o ponto de inflexão necessário na sociedade atual, como forma de resistência aos processos de expropriação das experiências que podemos ter na infância e na vida, de uma forma geral. Esta seria uma condição necessária, para pensarmos, por exemplo, com o devido rigor crítico, o alcance emancipatório dos projetos educativos.

\section{Considerações finais}

As considerações históricas atuais mostram, que os espaços para a realização de experiências formativas estão cada vez mais diminutos. O suposto desaparecimento da infância (POSTMAN, 1999) e a criação de uma "nova infância", cada vez mais massificada e influenciada pela mídia digital, tem gerado inúmeras questões e desafios para a Educação. 
O conceito de indústria cultural, cunhado por Adorno e Horkheimer (1985), traz uma série de elementos que nos ajudam a caracterizar o processo de empobrecimento da experiência do indivíduo, desde a infância. $\mathrm{O}$ fato de Adorno não ter discutido especificamente a questão da infância, não anula o potencial da crítica às interferências da indústria cultural na infância, uma vez que as criançasestão sendo cada vez mais cedo lançadas aos mecanismos sedutores da indústria cultural.

Os programas de televisão e os jogos digitaisestão cada vez mais presentes na vida das crianças, e estes à excitam tanto, que muitas não conseguem brincar de outra coisa a não ser com o seu Tablet ou Celular. Para além do consumo, o que as crianças estão perdendo são possibilidades de experiências formativas, como as narradas por Benjamin, em que a criança pode e deve criar os seus próprios brinquedos e jogos. A ludicidade, a criatividade, os sonhos e a imaginação estão sendo expropriados do mundo das crianças, e substituídos por desejos, imagens e sonhos criados pelos adultos que regem a indústria cultural.

Agamben (2005) ressalta, especificamente, como o conceito de infância, enquanto capacidade de potência, lugar propício para a experiência, ponto de partida para a condição humana, perpretada pela experiência e linguagem está sendo solapado pelas múltiplas situações e formas deempobrecimento das experiências humanas.

Para finalizar, o conceito de infância que procuramos caracterizar, a partir das considerações dos autores da Teoria Crítica, pode servir de contraponto crítico às iniciativas cada vez mais recorrentes de padronização ou singularizaçãoda infância. A infância, seja como estágio da vida humana, ou como potencialidade humana, precisa realizar as suas próprias experiências; tais como as brincadeiras que são imaginadas pelas crianças e que os adultos simplesmente ignoram, ou demoram muito para entender o real significado da experiência formativa.

\section{REFERÊNCIAS}

ADORNO, T. W. Teoria da semiformação. In: PUCCI, B.; ZUIN, A. A. S.; LASTÓRIA, L. C. N. (Org.). Teoria crítica e inconformismo: novas perspectivas de pesquisa. Campinas: Autores Associados, 2010. p.7-39.

ADORNO, T. W. Educação e emancipação. São Paulo: Paz e Terra, 1995.

ADORNO, T. W. Teoria estética. Lisboa: 70, 1970.

ADORNO, T.; HORKHEIMER, M. A industria cultural: o esclarecimento como mistificação das massas. In: ADORNO, T.; HORKHEIMER, M. Dialética do esclarecimento. Rio de Janeiro: Zahar, 1985. p.113-156. 
AGAMBEN, G. Infância e história: destruição da experiência e origem da história. Tradução de Henrique Burigo. Belo Horizonte: Ed. da UFMG, 2005.

ARIÉS, P. História social da criança e da família. 2.ed. Rio de Janeiro: Guanabara, 1973.

BENJAMIN, W. A hora das crianças. São Paulo: Nau Ed., 2015.

BENJAMIN, W. Reflexões sobre o brinquedo, a criança e a educação. São Paulo: 34, 2002.

BENJAMIN, W. Infância em Berlim por volta de 1900. In: BENJAMIN, W. Rua de mão única: obras escolhidas II. São Paulo: Brasiliense, 1993. p.71-142.

CALDERAN, A.; PEREZ, M. C. A. A construção histórico-cultural dos conceitos de infância e criança: apontamentos teóricos. In: CONGRESSO DE INICIAÇÃO CIENTÍFICA DA UNESP, 28., 2015, Araraquara. Anais... Araraquara: UNESP, 2015. Disponível em: <http://prope.unesp.br/cic_isbn/index.php?slcg=37\&mn=1>. Acesso em: 17 nov. 2017.

DUARTE, R. Teoria crítica da indústria cultural. Belo Horizonte: Ed. da UFMG, 2007.

HORKHEIMER, M. Teoria tradicional e teoria crítica. São Paulo: Abril, 1987.(Coleção os Pensadores).

KOHAN, W. O. Infância, estrangeiridade e ignorância: ensaios de filosofia e educação. Belo Horizonte: Autêntica, 2007.

MAAR, W. L.. Adorno, semiformação e educação. Educ. Soc., Campinas, v. 24, n. 83, ago. 2003.

MARCHI, R. de C. Walter Benjamin e infância: apontamentos impressionistas sobre sua(s) narrativa(s) a partir de narrativas diversas. Educação, Porto Alegre, v.34, n.2, p.221-229, 2011. Disponível em:

<http://revistaseletronicas.pucrs.br/ojs/index.php/faced/article/viewFile/7535/6360>. Acesso em: 17 nov. 2017.

MARX, K. Para a crítica da economia política. In: MARX, K. Manuscritos econômicos e filosóficos e outros textos escolhidos. São Paulo: Abril Cultural, 1978. p.107-138.

NOBRE, M. A teoria crítica. Rio de Janeiro: Zahar, 2004.

POSTMAN, N. O desaparecimento da infância. Tradução de Suzana Menescal. São Paulo: Graphia Editoral, 1999.

WIGGERSHAUS, R. A escola de Frankfurt: história, desenvolvimento teórico, significação política. São Paulo: Difel, 2002. 


\section{Como referenciar este artigo}

CALDERAN, Andréa.; GOMES, Luiz Roberto. Teoria crítica e infância: a caracterização do conceito no contexto de expropriação das experiências formativas. Doxa: Rev. Bras. Psicol. Educ., Araraquara, v.19, n.2, p. 270-282, jul./dez. 2017. e-ISSN: 2594-8385.

Submetido em: 04/06/2017

Aprovado em: 30/07/2017 